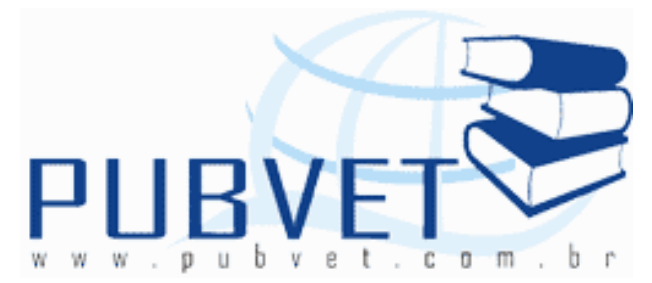

PUBVET, Publicações em Medicina Veterinária e Zootecnia.

\title{
Perfil de bovídeos abatidos nos matadouros oficiais do Estado do Amapá, Brasil
}

\author{
Bruna Viana Soares ${ }^{1}$, Claudiana Esteves ${ }^{2}$, Peter Bitencourt Faria ${ }^{3}$, Jacyara \\ Thais Teixeira ${ }^{4}$, Thiago Santos Araujo ${ }^{5}$
}

${ }^{1}$ Médica Veterinária. Fiscal Agropecuária do Estado do Amapá. Agência de Defesa e Inspeção Agropecuária do Amapá - DIAGRO. Mestre em Ciências Veterinárias. E-mail: drbrunasoares@yahoo.com.br

${ }^{2}$ Médica Veterinária. Aluna de Mestrado em Ciências Veterinárias, Universidade Federal de Lavras/DMV, claudianaesteves@yahoo.com.br

${ }^{3}$ Médico Veterinário. Professor Adjunto da Universidade Federal de Lavras UFLA. Doutor em Ciências dos Alimentos. E-mail: peter@dmv.ufla.br

${ }^{4}$ Nutricionista. Aluna de Doutorado em Ciência dos Alimentos, Universidade Federal de Lavras/DCA. Doutor em Ciências dos Alimentos. E-mail: jacynutricao@yahoo.com.br

${ }^{5}$ Biólogo. Mestre em Ciências Veterinárias. E-mail: thiagobiocouto@gmail.com

\section{Resumo}

O estado do Amapá é o único estado brasileiro cuja bubalinocultura supera quantitativamente a bovinocultura. Os dados referentes ao perfil do gado abatido nos estados são restritos aos órgãos de defesa e inspeção oficiais, portanto informações sobre a origem, a espécie e o quantitativo abatido tornam-se muitas vezes indisponíveis nos meios de consulta. O objetivo deste 
SOARES, B.V. et al. Perfil de bovídeos abatidos nos matadouros oficiais do Estado do Amapá, Brasil. PUBVET, Londrina, V. 8, N. 12, Ed. 261, Art. 1731, Junho, 2014.

trabalho foi analisar o gado bovídeo abatido em matadouros com Serviço de Inspeção Estadual - SIE no Amapá durante o ano de 2011, identificando o quantitativo dos animais em relação à origem, espécie, sexo, faixa etária e o meio de transporte utilizado quando encaminhados ao abate. Os dados utilizados neste estudo foram cedidos pela Gerência de Trânsito Agropecuário GTAGRO da Agência de Defesa e Inspeção Agropecuária do Estado do Amapá DIAGRO. Verificou-se que no estado do Amapá são abatidos mais bubalinos do que bovinos, e que o estado do Pará é o principal fornecedor de bovídeos para abate, onde se destacam os municípios de Chaves, Monte Alegre, Brasil Novo e Prainha. Os principais municípios amapaenses fornecedores foram Cutias, Macapá, Tartarugalzinho e Itaubal. O estado do Amapá forneceu mais bubalinos para abate, enquanto o estado do Pará forneceu mais bovinos. $O$ sexo predominante foi o masculino, a faixa etária mais abundante foi a de mais de 36 meses e o principal meio de transporte foi o marítimo/fluvial.

Palavras-chave: Bubalus bubalis, Defesa Agropecuária, Inspeção de Produtos de Origem Animal.

\section{Profile of bovine slaughtered in the state of Amapa, Brazil}

\section{Abstract}

The state of Amapá is the only Brazilian state whose buffalo production exceeds quantitatively cattle. The data relating to the profile of cattle slaughtered in the states are restricted to senior defense official inspection and therefore information on the origin, species, and quantitative slaughtered often become unavailable in the media query. The aim of this study was to analyze bovid cattle slaughtered in the State Inspection Service - SIE Amapá during the year 2011, identifying the amount of animals in relation to the origin, species, sex, age and means of transport. The data used in this study were provided by the Traffic Management Agriculture - GTAGRO Defense Agency and Agricultural Inspection Amapá State - DIAGRO. It was found that in the state of Amapá buffalo are slaughtered more than cattle, and that the state of 
SOARES, B.V. et al. Perfil de bovídeos abatidos nos matadouros oficiais do Estado do Amapá, Brasil. PUBVET, Londrina, V. 8, N. 12, Ed. 261, Art. 1731, Junho, 2014.

Pará is the leading provider of bovine for slaughter, where the highlights were the counties of Chaves, Monte Alegre, New Brazil and Prainha. The main suppliers were Cutias municipalities Amapa, Macapa, Tartarugalzinho and Itaubal. The state of Amapá provided more buffalo for slaughter, while the state of Pará provided more cattle. The predominant sex was male, age was the most abundant of more than 36 months and the main means of transportation was the sea / river.

Keywords: Bubalus bubalis, Defense Agriculture, Inspection of Products of Animal Origin.

\section{INTRODUÇÃO}

O Amapá apresenta como uma das particularidades da produção pecuária, um maior rebanho efetivo de bubalinos em relação ao de bovinos, condição essa que não é encontrada nos demais estados brasileiros. De acordo com a Pesquisa Municipal Pecuária realizada em 2012 pelo Instituto Brasileiro de Geografia e Estatística - IBGE (IBGE, 2013), o estado do Amapá mostrouse como o segundo maior produtor de bubalinos do Brasil, apresentando um quantitativo de 254.046 bubalinos, que representa cerca de18\% do rebanho nacional.

Diversamente do que se imaginava no passado, que a bubalinocultura estaria destinada a somente ocupar regiões consideradas inadequadas à criação de bovinos, o que se tem verificado, é que nas regiões em que os criadores lograram organizar cadeias agro-industriais, sua expansão tem sido expressiva e sua exploração vem se revelando alternativa relevante não só em propriedades de melhor nível tecnológico como, principalmente, nas pequenas explorações onde a bubalinocultura se tem mostrado importante fator de elevação da renda média e fixação do homem no campo (BERNARDES, 2007).

O búfalo é considerado um animal de tripla aptidão, pois se mostra adequado devido à sua força e resistência tanto como animal de tração, em especial em terrenos pantanosos ou inundados, como acontece em países da 
SOARES, B.V. et al. Perfil de bovídeos abatidos nos matadouros oficiais do Estado do Amapá, Brasil. PUBVET, Londrina, V. 8, N. 12, Ed. 261, Art. 1731, Junho, 2014.

Ásia, Índia e no Norte do Brasil, como para a produção de leite e carne, com alto valor agregado em seus produtos derivados, apresentando índices zootécnicos superiores àqueles normalmente encontrados em rebanhos bovinos (OLIVEIRA, 2005; VIEIRA et al., 2011 ).

O desempenho produtivo e o conforto térmico dos búfalos mantidos em sistemas silvipastoris são superiores à média dos sistemas tradicionais por fornecer sombreamento e melhorar o conforto animal, favorecendo a sustentabilidade da atividade pecuária nos aspectos produtivos, biológicos, econômicos, sociais e ecológicos (CASTRO et al., 2008).

De acordo com o Manual de Preenchimento para Emissão de Guia de Trânsito Animal de Bovinos e Bubalinos Versão 16.0 (BRASIL, 2013), atualmente, as exigências de vacinação para trânsito de bovinos e bubalinos estão limitadas à febre aftosa e brucelose. No caso da febre aftosa, no momento, somente no Estado de Santa Catarina a vacinação não é realizada. Nas demais unidades da Federação, a vacinação é obrigatória e exigida para o trânsito dos animais. Portanto torna-se obrigatória a apresentação da GTA durante o trânsito e desembarque de bovídeos em estabelecimentos de abate, só sendo permitida a matança de animais vacinados e com a origem comprovada. A espécie, o sexo, a quantidade de animais, a marca do rebanho, a origem, o destino, a finalidade, o tipo de meio de transporte, as vacinações e os atestados de sanidade são informações presentes na GTA, bem como seu local e data de emissão, validade e dados do emissor.

Publicações científicas sobre temas que abordem defesa agropecuária e inspeção de produtos de origem animal são escassos. Dados e registros sobre as características do gado abatido nos matadouros oficiais do estado do Amapá são restritos aos órgãos oficiais. O objetivo deste estudo foi analisar o perfil do gado bovídeo abatido em matadouros com Serviço de Inspeção Estadual - SIE no Amapá durante o ano de 2011, identificando o quantitativo dos animais em relação à origem, a espécie, faixa etária e meio de transporte principal. 
SOARES, B.V. et al. Perfil de bovídeos abatidos nos matadouros oficiais do Estado do Amapá, Brasil. PUBVET, Londrina, V. 8, N. 12, Ed. 261, Art. 1731, Junho, 2014.

\section{MATERIAL E MÉTODOS}

Os dados utilizados neste estudo foram cedidos pela Gerência de Trânsito (GTAGRO) da DIAGRO (Agência de Defesa e Inspeção Agropecuária do Estado do Amapá), através de informações contidas nas Guias de Trânsito Animal (GTA) recolhidas pelo Serviço de Inspeção Estadual durante o ano de 2011. Para que o perfil de abate oficial do estado do Amapá fosse traçado, foram analisadas a origem, o sexo, a faixa etária, o meio de transporte, a quantidade e a espécie dos bovídeos abatidos no matadouro Frigorífico Amazônia Empreendimentos Ltda. (FRIAAP), localizado no município de Macapá-AP, e no matadouro Braga Empreendimentos Ltda. (FRIMAP), localizado no município de Santana-AP. O software Microsoft Office Excel $2010^{\circledR}$ foi utilizado para processamento dos dados e elaboração das tabelas e figuras.

Para o estudo, foi utilizada análise descritiva dos dados, de forma a descrever as características encontradas para cada variável analisada.

\section{RESULTADOS E DISCUSSÃO}

Em Macapá-AP foram abatidos 26.377 bovídeos, dos quais 18.387 eram originários do estado Pará e 7.990 originários do estado do Amapá (Figura 1), predominando a espécie bovina sobre a bubalina. Em Santana-AP foram abatidos 44.288 bovídeos, 20.493 originários do Pará e 23.795 do Amapá, predominando a espécie bubalina sobre a bovina (Figura 2 ). De um total de 70.665 de bovídeos abatidos no estado do Amapá, 38.880 foram trazidos do Pará, e a espécie mais abundante foi à bubalina (Figura 3). 
SOARES, B.V. et al. Perfil de bovídeos abatidos nos matadouros oficiais do Estado do Amapá, Brasil. PUBVET, Londrina, V. 8, N. 12, Ed. 261, Art. 1731, Junho, 2014.

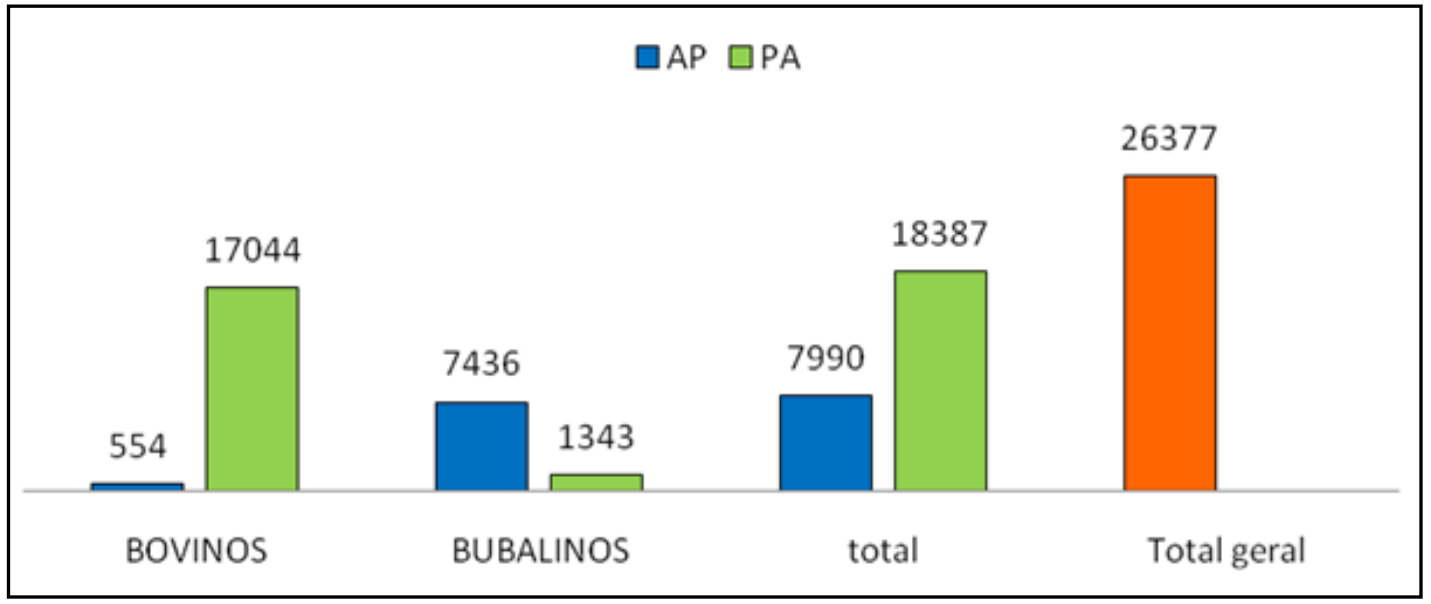

Figura 1 - Origem e quantitativo de bovídeos abatidos em Macapá-AP no ano de 2011. AP = Amapá; PA = Pará.

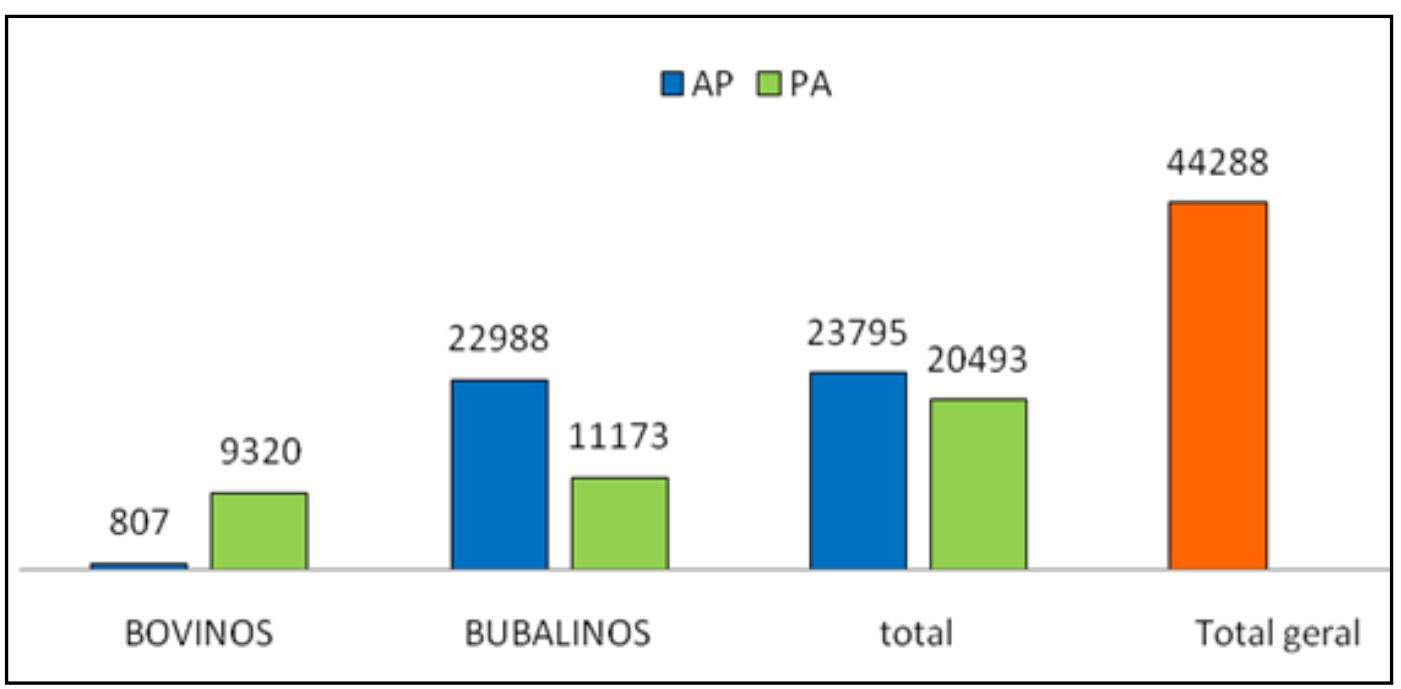

Figura 2 - Origem e quantitativo de bovídeos abatidos em Santana/AP no ano de 2011. AP = Amapá; PA = Pará. 


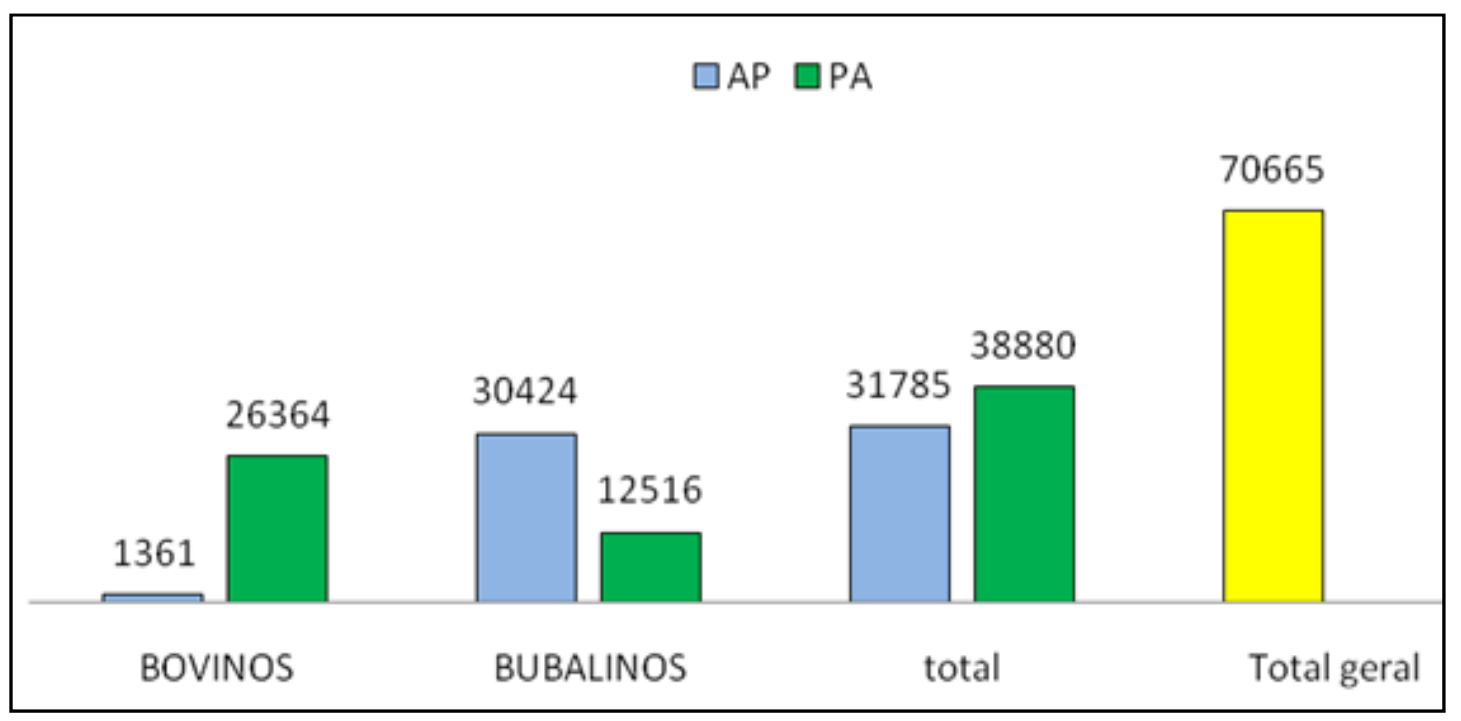

Figura 3 - Origem e quantitativo dos bovídeos abatidos no Amapá em 2011. $\mathrm{AP}=$ Amapá; $\mathrm{PA}=$ Pará.

Pôde-se observar que o estado do Amapá forneceu para o abate mais bubalinos do que bovinos (Figuras 1,2 e 3 ). Isto pode ser explicado pelo fato de predominar no estado a criação de bubalinos, cujo quantitativo supera o de gado bovino (Tabela 1). Esta particularidade faz do estado do Amapá o único estado brasileiro cuja bubalinocultura supera quantitativamente a bovinocultura, predominando a pecuária extensiva não tecnificada (IBGE, 2012).

Tabela 1 - Efetivo dos rebanhos por tipo de rebanho, referente ao censo de 2012

\begin{tabular}{lccc}
\hline & Bovinos & Bubalinos & Total \\
\hline Brasil & 211.279 .082 & 4.523 .657 & 215.802 .739 \\
Pará & 18.605 .051 & 454.079 & 19.059 .130 \\
Amapá & 142.825 & 254.046 & 396.871
\end{tabular}


SOARES, B.V. et al. Perfil de bovídeos abatidos nos matadouros oficiais do Estado do Amapá, Brasil. PUBVET, Londrina, V. 8, N. 12, Ed. 261, Art. 1731, Junho, 2014.

Os principais fornecedores de gado bovídeo para abate do estado do Amapá foram os municípios de Cutias, Macapá, Tartarugalzinho e Itaubal (Figura 4). Dentre os municípios paraenses destacaram-se Chaves, Monte Alegre, Brasil Novo e Prainha (Figuras 5 e 6).

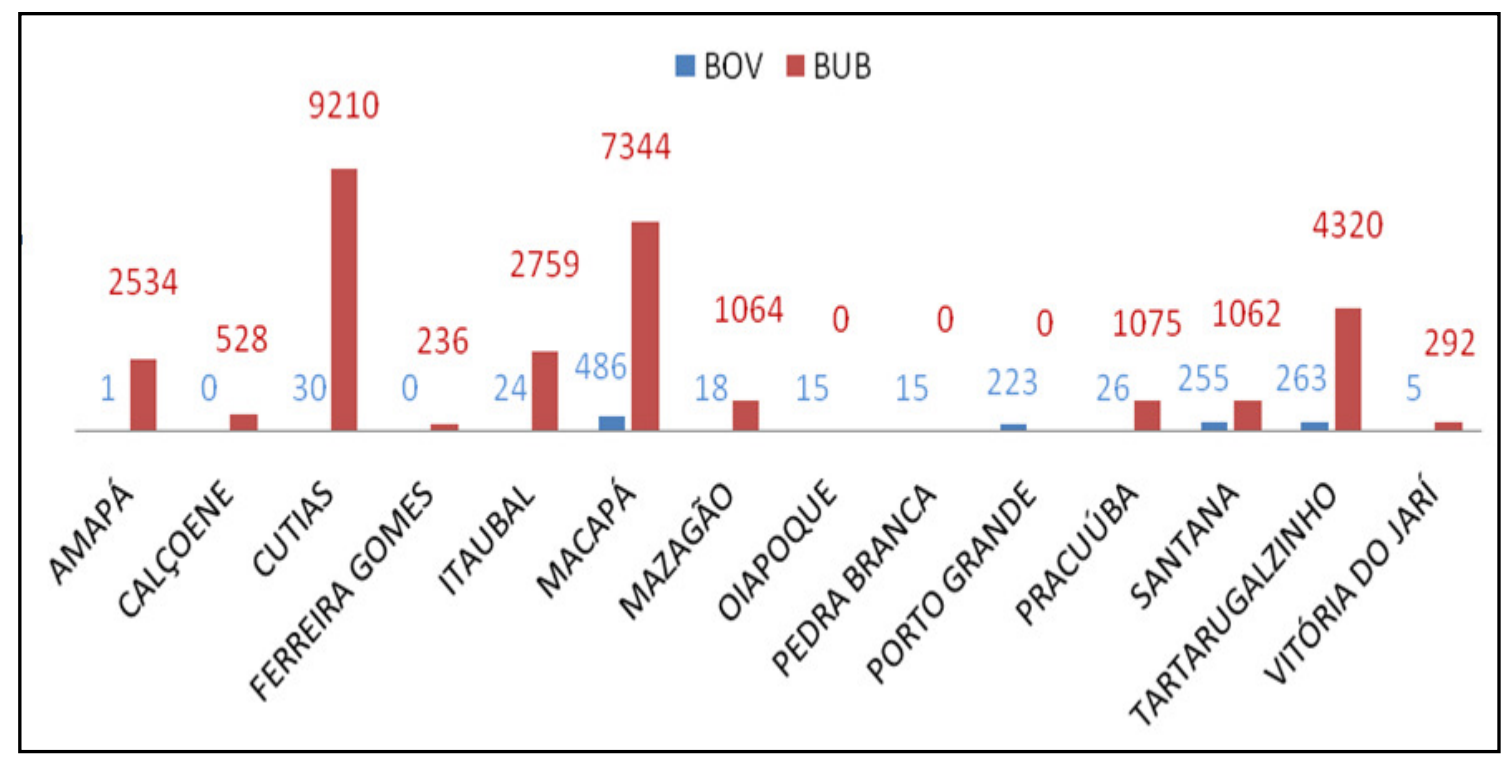

Figura 4 - Municípios amapaenses fornecedores de gado bovídeo para abate no estado do Amapá no ano de 2011 
SOARES, B.V. et al. Perfil de bovídeos abatidos nos matadouros oficiais do Estado do Amapá, Brasil. PUBVET, Londrina, V. 8, N. 12, Ed. 261, Art. 1731, Junho, 2014.

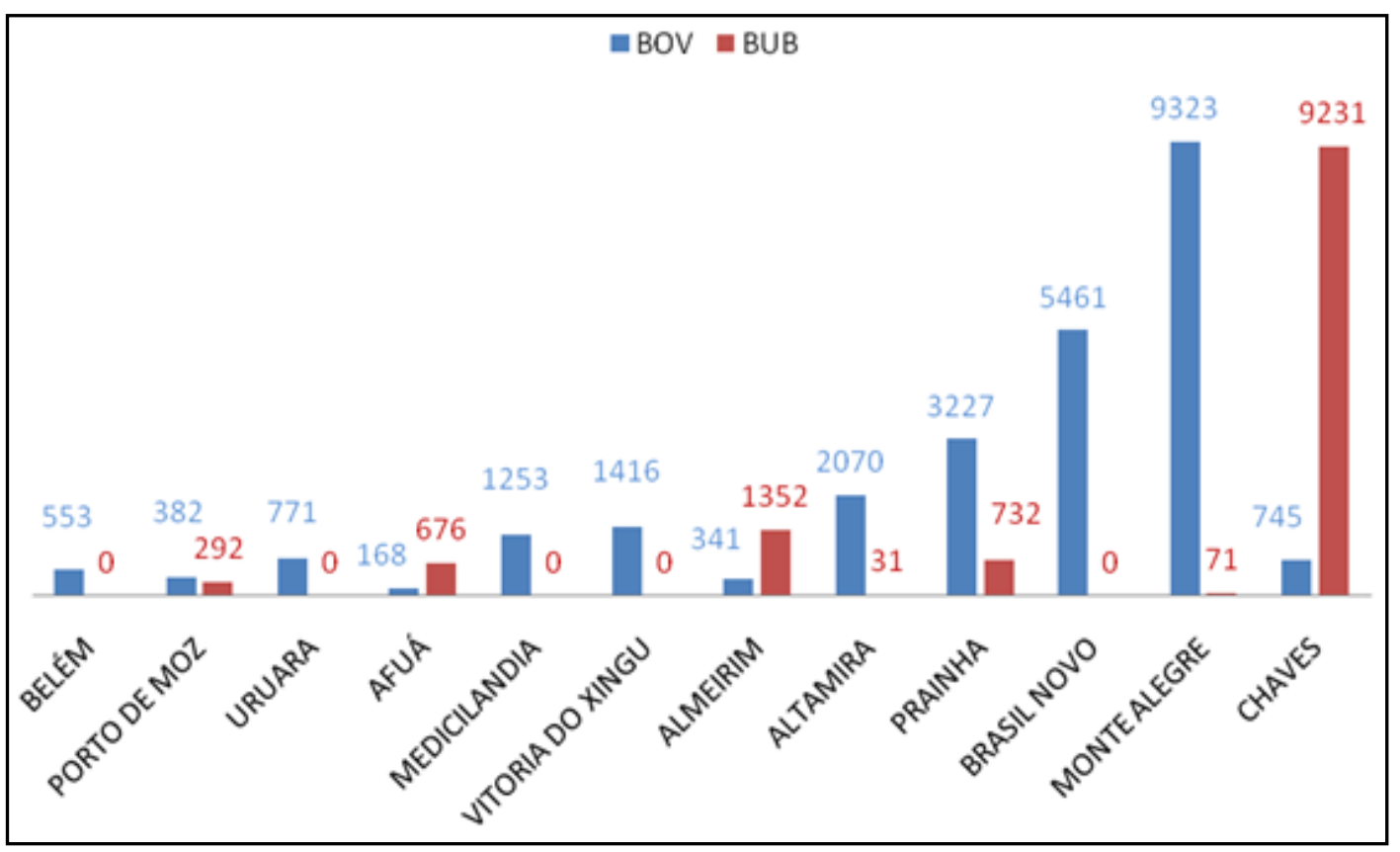

Figura 5 - Principais municípios paraenses fornecedores de gado bovídeo para abate no estado do Amapá no ano de 2011

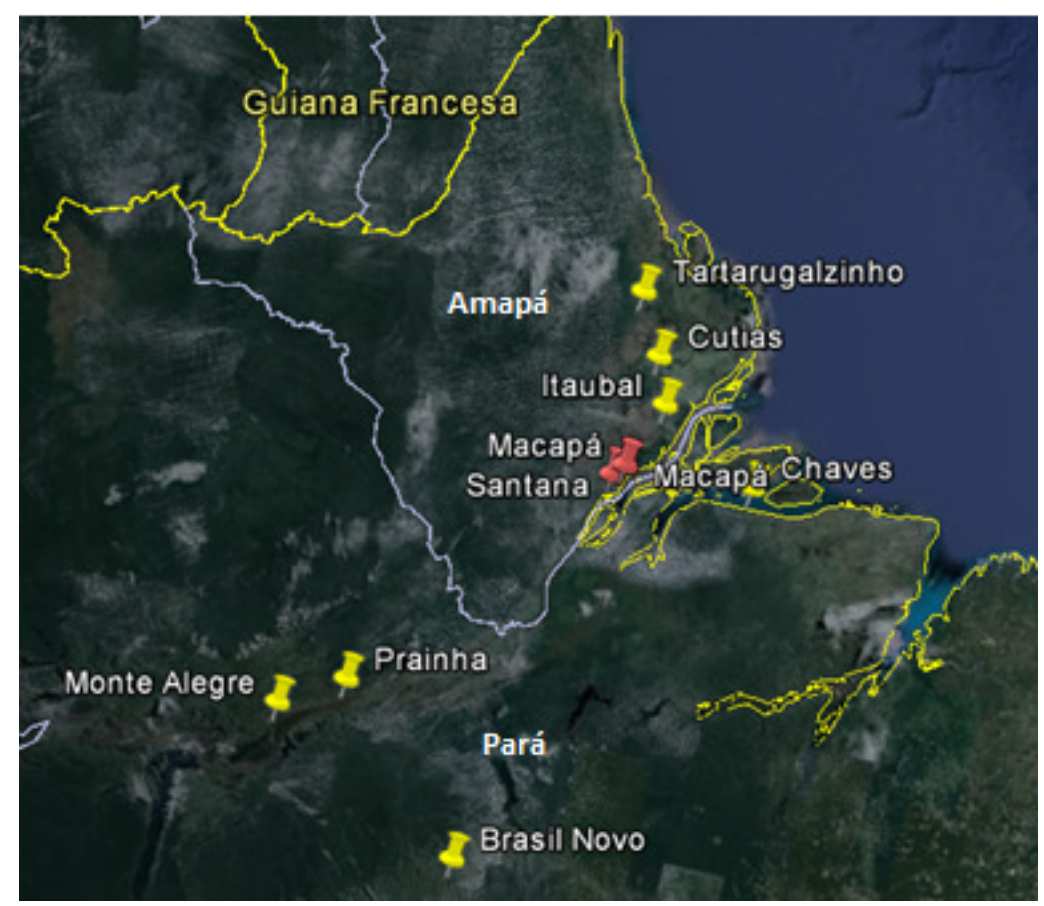

Figura 6 - Mapa do Amapá e Norte do Pará. Em destaque os principais municípios fornecedores de gado bovídeo para abate nos matadouros oficiais do Amapá. Fonte: Google Earth (2012). 
SOARES, B.V. et al. Perfil de bovídeos abatidos nos matadouros oficiais do Estado do Amapá, Brasil. PUBVET, Londrina, V. 8, N. 12, Ed. 261, Art. 1731, Junho, 2014.

Foram analisadas um total de 713 GTA's, das quais 402 foram emitidas no Pará e 311 no Amapá. Em relação aos meios de transporte utilizados para o trânsito animal, a análise das GTA's mostrou que o meio de transporte predominante é o marítimo/fluvial, seguido pelo rodoviário (Tabela 2). A totalidade dos animais destinados do Pará chegou aos matadouros por via marítima/fluvial. Esse fato se deve à ausência de rodovias de acesso entre os estados do Amapá e Pará, o que torna o transporte fluvial indispensável para o trânsito de bovídeos (Figura 6). Em contrapartida, os animais oriundos do Amapá realizaram trânsito tanto rodoviário quanto marítimo/ fluvial, em proporções semelhantes.

Além dos meios de transporte rodoviário e marítimo/fluvial, existem na GTA os meios a pé, ferroviário e aéreo, porém os mesmos não foram utilizados para o trânsito dos bovídeos destinados ao abate no Amapá em 2011.

Tabela 2 - Meios de transporte utilizados para o transporte de bovídeos para abate no estado do Amapá no ano de 2011, de acordo com a GTA. Outros: a pé, ferroviário e aéreo.

\begin{tabular}{|c|c|c|c|c|c|}
\hline \multirow[t]{2}{*}{ Estado } & \multirow[t]{2}{*}{ Espécie } & \multicolumn{3}{|c|}{ Meios de transporte } & \multirow[t]{2}{*}{ Total } \\
\hline & & Rodoviário & Marítimo/ Fluvial & Outros & \\
\hline \multirow[t]{2}{*}{ Amapá } & Bovinos & 45 & 57 & 0 & 102 \\
\hline & Bubalinos & 102 & 107 & 0 & 209 \\
\hline \multirow[t]{2}{*}{ Pará } & Bovinos & 0 & 332 & 0 & 332 \\
\hline & Bubalinos & 0 & 70 & 0 & 70 \\
\hline \multicolumn{2}{|c|}{ Total } & 147 & 566 & 0 & 713 \\
\hline
\end{tabular}

Fonte: DIAGRO (2012)

A Tabela 3 demonstra a relação entre sexo, faixa etária, origem e espécie dos bovídeos abatidos no Amapá em 2011. Em relação ao sexo; 68,7\% dos animais eram machos e, 31,3\% fêmeas. A faixa etária de abate predominante foi a de mais de 36 meses $(47,8 \%)$, seguida das faixas etárias 
de 25 a 36 meses $(33,6 \%)$, de 13 a 24 meses $(14,1 \%)$ e de 0 a 12 meses $(4,5 \%)$. Em todas as faixas etárias e em ambas as espécies, o número de machos abatidos foi superior ao de fêmeas, exceto nos bovinos amapaenses de 13 a 14 meses, onde o número de fêmeas abatidas foi superior ao de machos (Tabela 3).

Tabela 3 - Número de animais em relação ao sexo, faixa etária, origem e espécie dos bovídeos destinados ao abate no estado do Amapá em 2011, de acordo com informações contidas nas GTA's.

\begin{tabular}{|c|c|c|c|c|c|c|c|c|c|c|}
\hline \multirow{3}{*}{ Estado } & \multirow{3}{*}{ Espécie } & \multicolumn{8}{|c|}{ Idade } & \multirow{3}{*}{ Total } \\
\hline & & \multicolumn{2}{|c|}{$\begin{array}{l}0 \text { a } 12 \\
\text { meses }\end{array}$} & \multicolumn{2}{|c|}{$\begin{array}{c}13 \text { a } 24 \\
\text { meses }\end{array}$} & \multicolumn{2}{|c|}{$\begin{array}{l}24 \text { a } 36 \\
\text { meses }\end{array}$} & \multicolumn{2}{|c|}{$\begin{array}{c}\text { Mais de } 36 \\
\text { meses }\end{array}$} & \\
\hline & & $M$ & $\mathbf{F}$ & $M$ & $\mathbf{F}$ & $\mathbf{M}$ & $\mathbf{F}$ & $\mathbf{M}$ & $\mathbf{F}$ & \\
\hline \multirow[t]{2}{*}{ Amapá } & Bubalinos & 1001 & 213 & 2275 & 1104 & 7542 & 2768 & 10020 & 5501 & 30424 \\
\hline & Bovinos & 305 & 78 & 55 & 72 & 186 & 174 & 291 & 200 & 1361 \\
\hline \multirow[t]{2}{*}{ Pará } & Bubalinos & 397 & 302 & 2301 & 706 & 2574 & 2002 & 2232 & 2002 & 12516 \\
\hline & Bovinos & 502 & 382 & 2214 & 1237 & 6009 & 2488 & 10662 & 2870 & 26364 \\
\hline Total & & 2205 & 975 & 6845 & 3119 & 16311 & 7432 & 23205 & 10573 & 70665 \\
\hline \multicolumn{2}{|c|}{$\begin{array}{l}\text { Total por faixa } \\
\text { etária }\end{array}$} & \multicolumn{2}{|c|}{3180} & \multicolumn{2}{|c|}{9964} & \multicolumn{2}{|c|}{23743} & \multicolumn{2}{|c|}{33778} & 70665 \\
\hline \multicolumn{2}{|c|}{ Total(\%) } & \multicolumn{2}{|c|}{4,5} & \multicolumn{2}{|c|}{14,1} & \multicolumn{2}{|c|}{33,6} & \multicolumn{2}{|c|}{47,8} & 100 \\
\hline
\end{tabular}

$M=$ Macho; F = Fêmea

Fonte: DIAGRO (2012)

\section{CONCLUSÕES}

O gado bovídeo abatido no estado do Amapá em 2011 foi em sua maioria da espécie bubalina, do sexo masculino e da faixa etária de mais de 36 meses. A origem predominante foi o Estado do Pará, sendo o Pará o principal fornecedor de bovinos e o Amapá o principal fornecedor de bubalinos. Isso 
SOARES, B.V. et al. Perfil de bovídeos abatidos nos matadouros oficiais do Estado do Amapá, Brasil. PUBVET, Londrina, V. 8, N. 12, Ed. 261, Art. 1731, Junho, 2014.

define a importância da bubalinocultura na pecuária amapaense, como fonte de renda e alimentação para a população local.

O meio de transporte marítimo/fluvial foi exclusivo no transporte de animais do Pará para o Amapá, devido a inexistência de rodovias entre os dois estados, porém os animais oriundos do Amapá transitaram tanto por via rodoviária, quanto por via marítimo/fluvial, em proporções semelhantes. Esse meio de transporte é indispensável para o trânsito animais no norte da Amazônia Ocidental e a fiscalização agropecuária deve ser intensificada nos rios amazônicos, visto o intenso trânsito intermunicipal e a complexidade geográfica da região.

\section{REFERÊNCIAS BIBLIOGRAFICAS}

AMAPÁ. Lei n. 0701, de 28 de junho de 2002. Cria a Agência de Defesa e Inspeção Agropecuária do Estado do Amapá - DIAGRO e dá outras providências. Diário Oficial do Estado do Amapá, Macapá, n. 2816, de 01 de julho de 2002.

BERNARDES, O. Bubalinocultura no Brasil: situação e importância econômica. Rev. Bras. Reprod. Anim., Belo Horizonte, v.31, n.3, p.293-298, jul/set. 2007.

BRASIL. Manual de Preenchimento para Emissão de Guia de Trânsito Animal de Bovinos e Bubalinos Versão 16.0. Departamento de Saúde Animal - DSA, Ministério da Agricultura,

Pecuária e Abastecimento - MAPA. Disponível em: www.agricultura.gov.br. Acesso em: 28 out. 2013.

CASTRO, A.C. et al. Sistema silvipastoril na Amazônia: ferramenta para elevar o desempenho produtivo de búfalos. Ciência Rural, Santa Maria, v.38, n.8, p.2395-2402, nov, 2008.

instituto brasileiro de geografia e estatísticA. Pesquisa Municipal Pecuária 2012. Rio de Janeiro. Disponível em: http://www.ibge.gov.br/estadosat/index.php . Acesso em: 28 out. 2013.

GOOGLE EARTH. Disponível em: https://maps.google.com.br/maps?hl=ptBR\&tab=wl\&q=google Acesso em: 29 out. 2013

OLIVEIRA, A. L. Búfalos: produção, qualidade de carcaça e de carne. Alguns aspectos quantitativos, qualitativos e nutricionais para promoção do melhoramento genético. Rev. Bras. Reprod. Anim., Belo Horizonte, v.29, n.2, p.122-134, abril/jun. 2005.

VIEIRA, J.N., et al. Bubalinocultura no Brasil: Short communication. PUBVET, Londrina, v. 5, n. 2, ed. 149, art. 1003, 2011. 